\title{
Influence of light activation of simplified adhesives on the shear bond strength of resin cements to a leucite-reinforced ceramic
}

\author{
Adilson Yoshio Furuse ${ }^{1}$, Cassiana Koch Scotti ${ }^{1}$, Alfredo Llerena-Icochea ${ }^{1}$, \\ Juliana Fraga Soares Bombonatti ${ }^{1}$, Gisele Aihara Haragushiku ${ }^{2}$, Carla Castiglia Gonzaga ${ }^{2}$
}

Correspondence: Dr. Juliana Fraga Soares Bombonatti

Email: julianafraga@usp.br

\begin{abstract}
'Department of Operative Dentistry, Endodontics and Dental Materials, Bauru School of Dentistry, University of São Paulo, São Paulo, Brazil,

${ }^{2}$ Graduate Program in Dentistry, Positivo University, Curitiba, Brazil
\end{abstract}

\section{ABSTRACT}

Objective: This study aims to evaluate the influence of the light activation of simplified adhesives on the shear bond strength of resin cements to a glass-ceramic. Three factors were evaluated: (1) cement in two levels (light cured and dual cured); (2) adhesive in two levels (Single Bond 2 and Single Bond Universal), and (3) light activation in two levels (yes or no). Materials and Methods: Thirty-two 1-mm thick slices of a leucite-reinforced glass-ceramic (IPS Empress CAD) were divided into eight groups according to adhesive (Single Bond 2 or Single Bond Universal), cement (AllCem Veneer or AllCem), and light activation of the adhesive before application of the cement (yes or no). Ceramic surfaces were etched for $60 \mathrm{~s}$ with $5 \%$ hydrofluoric acid, and adhesives were applied. Four cement cylinders were made over each ceramic slice $(n=16)$ and then submitted to shear bond strength tests. Statistical Analysis: Data were analyzed with three-way ANOVA and Tukey $(\alpha=0.05)$. Results: There were significant differences between adhesives $(P<0.0001)$ and no differences between cements $(P=0.0763)$ and light activation $(P=0.4385)$. No interaction effect occurred $(P=0.05)$. Single Bond 2 showed higher bond strength than Single Bond Universal. Conclusions: The light activation of the adhesive before the application of the resin cement did not influence the bond strength.

Key words: Ceramics, dental adhesives, shear bond strength

\section{INTRODUCTION}

Dental ceramics are among the main materials due to their well-recognized esthetic properties, precision, biocompatibility, and strength. ${ }^{[1-3]}$ Despite physical and mechanical properties, the marginal adaption after cementing is still a concern. Acid-sensitive ceramics, such as glass-ceramics, require etching with hydrofluoric acid and a silane-coupling agent, followed by an adhesive for bonding between the resin cement

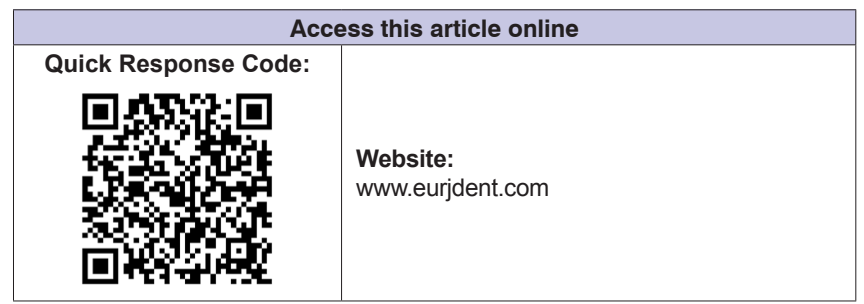

and the ceramics. ${ }^{[4-6]}$ Although the light activation of the adhesive before cementation is recommended, ${ }^{[7,8]}$ the fit of the restoration may be impaired if there is adhesive excess. To avoid this problem, an alternative is applying the adhesive without light activating it before applying the resin cement. However, the influence of this nonlight-activation technique on

This is an open access article distributed under the terms of the Creative Commons Attribution-NonCommercial-ShareAlike 3.0 License, which allows others to remix, tweak, and build upon the work non-commercially, as long as the author is credited and the new creations are licensed under the identical terms.

For reprints contact: reprints@medknow.com

How to cite this article: Furuse AY, Scotti CK, Llerena-Icochea A, Bombonatti JF, Haragushiku GA, Gonzaga CC. Influence of light activation of simplified adhesives on the shear bond strength of resin cements to a leucite-reinforced ceramic. Eur J Dent 2018;12:3-6.

DOI: 10.4103/ejd.ejd_307_17 
the bond strength of resin-based cements to ceramics still needs evaluation as the compatibility between cements and adhesives is important. The nonlight activation could generate unwanted chemical reactions, depending on type of cement, $\mathrm{pH}$, and hydrophilicity of adhesives..$^{[9-13]}$

Among adhesive systems, universal (multimode or multipurpose) share a wide versatility and high performance due to their composition. The addition of silane-coupling agents could promote adhesion between intrinsically different materials such as resin cements and ceramics. However, the $\mathrm{pH}$ of universal adhesives (around 2.7-3.0) could lead to lower compatibility with dual-cured cements when used without activators such as arylsulfinate salts.

Considering differences between dual-cured and light-cured resin cements and the potential incompatibility between simplified adhesives and dual-cured cements when adhesives are not light activated before cementation, this study evaluated the influence of light-activating simplified adhesives on the shear bond strength of resin cements to a leucite-reinforced glass-ceramic. Null hypotheses were that there would be no differences between shear bond strengths of (i) two simplified adhesives; (ii) two resin cements; and (iii) two adhesive light-activation protocols.

\section{MATERIALS AND METHODS}

Thirty-two 1-mm thick slices obtained from leucite-reinforced ceramic blocks (IPS Empress CAD, Ivoclar Vivadent, Liechtenstein) were embedded in 3/4" Polyvinyl chloride tubes with self-curing acrylic resin and then polished (Ecomet Buehler, Lake Bluff/IL, USA) with sandpapers (granulometry \#400 to \#600) under water cooling.

Slices were etched for $60 \mathrm{~s}$ with $5 \%$ hydrofluoric acid (Condac Porcelana, FGM, Joinville/SC, Brazil) and divided into eight groups according to the adhesive (two-step etch-and-rinse [Single Bond 2, 3M ESPE, St. Paul/MN, EUA] or one-bottle universal adhesive [Single Bond Universal, 3M ESPE]), resin cement (dual cured [AllCem, FGM] and light cured [AllCem Veneer, FGM]) and light activation of the adhesive (light activation or nonlight activation). Light activation was performed with a light-emitting diode (LED) device (Valo Cordless, Ultradent, South Jordan/UT, USA) with irradiance of $1000 \mathrm{~mW} / \mathrm{cm}^{2}$ for the manufacturer's recommended time.
For Single Bond 2 groups, a silane-coupling agent (Prosil, FGM) was applied for $1 \mathrm{~min}$, followed by 5 -s air drying, before adhesive application. Single Bond Universal was used without silane-coupling agent as follows: application and waiting for $10 \mathrm{~s}, 10$-s solvent evaporation, and 10-s light activation (depending on the group). Materials are described in Table 1.

Resin cement cylinders were fabricated with surgical catheters (inner diameter of $1.40 \mathrm{~mm}$ and height of $1 \mathrm{~mm}$ ). Four cylinders per ceramic substrate were made (16 cylinders per group). Resin cements were inserted in the catheters and light activated for $20 \mathrm{~s}$ with the same LED device. After 10-min waiting, catheters were removed with \#12 scalpel blades to expose cement cylinders. Samples were stored in $37^{\circ} \mathrm{C}$ deionized water for $24 \mathrm{~h}$ and then submitted to the shear bond strength evaluation (Instron, High Wycombe, United Kingdom) using a $0.2-\mathrm{mm}$ wire loop and $0.5 \mathrm{~mm} / \mathrm{min}$ crosshead speed. A stereomicroscope was used to evaluate the type of failure: adhesive, cohesive in cement, cohesive in ceramic, and mixed. Data were analyzed with three-way ANOVA and Tukey $(\alpha=5 \%)$.

\begin{tabular}{|c|c|c|}
\hline Material & Brand & Composition \\
\hline $\begin{array}{l}\text { Universal } \\
\text { adhesive }\end{array}$ & $\begin{array}{l}\text { Scotchbond } \\
\text { Universal } \\
\text { (3M ESPE) }\end{array}$ & $\begin{array}{l}\text { Hydroxyethyl methacrylate, } \\
\text { BisGMA, decamethylene } \\
\text { dimethacrylate, ethanol, } \\
\text { silane-treated silica, water, } \\
\text { 2-propenoic acid, 2-methyl, } \\
\text { 10-decanediol, phosphorous } \\
\text { oxide, copolymer of acrylic and } \\
\text { itaconic acid, dimethylaminoethyl } \\
\text { methacrylate, camphorquinone, } \\
\text { dimethylaminobenzoate, } \\
\text { 2-6-di-tert-butyl-p-cresol }\end{array}$ \\
\hline $\begin{array}{l}\text { Self-etching } \\
\text { adhesive }\end{array}$ & $\begin{array}{l}\text { Adper Single } \\
\text { Bond } 2(3 \mathrm{M} \\
\text { ESPE) }\end{array}$ & $\begin{array}{l}\text { Methacrylic monomers } \\
\text { (BisGMA/HEMA), dimethacrylates, } \\
\text { ethanol, water, methacrylate } \\
\text { functional copolymer of } \\
\text { polyacrylic, polyitaconic acid }\end{array}$ \\
\hline $\begin{array}{l}\text { Dual-cured } \\
\text { resin cement }\end{array}$ & $\begin{array}{l}\text { AllCem } \\
\text { (FGM) }\end{array}$ & $\begin{array}{l}\text { Base paste: Methacrylic monomers } \\
\text { (TEGDMA/BisEMA/BisGMA), } \\
\text { camphorquinone, coinitiators, } \\
\text { barium, aluminum-silicate glass } \\
\text { microparticles, silicone dioxide } \\
\text { nanoparticles, inorganic pigments } \\
\text { Catalyst: Methacrylic monomers, } \\
\text { dibenzoil, peroxide and } \\
\text { stabilizers, aluminum silicate } \\
\text { glass microparticles }\end{array}$ \\
\hline $\begin{array}{l}\text { Light-activated } \\
\text { resin cement }\end{array}$ & $\begin{array}{l}\text { AllCem } \\
\text { Veneer } \\
\text { (FGM) }\end{array}$ & $\begin{array}{l}\text { Methacrylic monomers, } \\
\text { camphorquinone, } \\
\text { coinitiators, pigments, } \\
\text { barium-aluminum-silicate silanized } \\
\text { glass particles and silicone dioxide }\end{array}$ \\
\hline \multicolumn{3}{|c|}{$\begin{array}{l}\text { BisGMA: Bisphenol A diglycidyl ether dimethacrylate, } \\
\text { TEGDMA: Triethylene glycol dimethacrylate, BisBMA: Bisphenol } \\
\text { A glycol dimethacrylate, HEMA: Hydroxyethyl methacrylate }\end{array}$} \\
\hline
\end{tabular}


Furuse, et al.: Influence of the light activation on bond strength of resin cements to a ceramic

\section{RESULTS}

Table 2 shows means and standard deviations. There were significant differences between adhesives $(P<0.0001)$. Higher overall shear bond strength values were observed with Single Bond Universal. There were no differences between resin cements $(P=0.0763)$ and light-activation protocols $(P=0.4385)$. Double and triple interactions were not significant $(P>0.05)$.

\section{DISCUSSION}

The influence of scanning accuracy of computer-aided design-computer-aided manufacturing systems, dental preparation, and polishing step on marginal and internal adaptation of ceramic systems have been investigated. ${ }^{[14-17]}$ However, the nonlight activation of adhesives during the cementation is an important factor that is closely related to clinical procedures and certainly is a reason of concern among clinicians, especially when universal adhesives are employed. The nonlight activation of adhesives not only would allow reducing operative steps and easing the adaption of prosthetic restorations but also could simplify the cementation by reducing technique sensitivity. For this reason, the present study was designed to address the bond strength using two different categories of simplified adhesives, including a universal one, with light-cured and dual-cured resin cements. According to the results, the only null hypothesis accepted was that there would be no differences between adhesives. Thus, the chemical incompatibility between the evaluated simplified adhesives and the dual-cured resin cement was not significant, which differs from the idea that simplified adhesives are incompatible to dual-cured resin cements. ${ }^{[18,19]}$

The present study shows that there was no direct relationship between shear bond strength and resin cements (i.e., light cured and dual cured). The absence

\begin{tabular}{llcc}
$\begin{array}{l}\text { Table 2: Shear bond strength means and standard } \\
\text { deviations }\end{array}$ & Cement & $\begin{array}{c}\text { Light-activation } \\
\text { protocol for the } \\
\text { adhesive layer }\end{array}$ & $\begin{array}{c}\text { Shear bond } \\
\text { strength (MPa) }\end{array}$ \\
\hline Adhesive & YllCem & Yes & $18.53(4.6)$ \\
Single Bond & Veneer & No & $18.47(5.6)$ \\
Universal & Vent & Yes & $19.06(11.3)$ \\
& AllCem & No & $22.06(5.2)$ \\
Single & AllCem & Yes & $13.47(3.9)$ \\
Bond 2 & Veneer & No & $14.01(5.4)$ \\
& AllCem & Yes & $15.76(5.34)$ \\
& & No & $15.48(4.17)$ \\
\hline
\end{tabular}

of difference between cements could be explained by the fact that the light activation was performed directly over the cement. Thus, it is assumed that most of the reaction happened at the expense of the light activation for both cements because all specimens were light activated immediately rather than waiting for chemical polymerization. It is noteworthy that delaying light activation could impact properties of dual-cured resin cements. ${ }^{[20]}$ Furthermore, in a clinical situation, the ceramics thickness may play a major role on the light activation. Depending on the type, thickness, and color of the ceramic, the radiant exposure may not be enough due to attenuation, compromising the polymerization process. ${ }^{[21-24]}$

In the present study, factors such as thickness and composition of ceramic, light transmittance through the ceramic material, characteristics of the lightcuring device, radiant exposure, and concentration of hydrofluoridric acid were not evaluated. For this reason, results of this study could be different not only if the ceramics were interposed but also if many other factors were changed.

Regarding the bonding agents, results obtained are in accordance with other studies. ${ }^{[25-27]}$ The present study found higher overall shear bond strength for the universal adhesive. This may be explained by the idea that universal adhesives do not share the particularities of other simplified etch-and-rinse systems. ${ }^{[26,28]}$ In the case of simplified self-etching adhesives, due to the poorly polymerized oxygen-inhibited layer, the residual acidic resin monomers may react with basic catalytic components such as tertiary amines by bimolecular redox reaction which involves an electron transfer that prevents the generation of free radicals and compromises the chemical reaction. ${ }^{[19]}$

The presence of 10-methacryloyloxydecyl dihydrogen phosphate monomer in Single Bond Universal could explain the best results due to the fact that hydroxyl groups may chemically react with the resin cement and the glass-ceramic phase. Moreover, the incorporation of a silane-coupling agent in this material could improve the interaction with silica through covalent bonds, avoiding the formation of contaminating layers that could weaken bond strength. ${ }^{[29]}$

The shear bond strength method was used instead of a tensile one since it may predict lateral forces and avoid pretesting failures since it is less technique sensitive during specimen preparation. The use of wire loop may lead to a better stress distribution at the 
Furuse, et al.: Influence of the light activation on bond strength of resin cements to a ceramic

bonding area, unlike the severe stress concentration at the load application area by knife-edge chisels. ${ }^{[30]}$ In addition, the small bonding area of cement cylinders decreases the likelihood of a critical flaw being present. Regarding the bond durability and aging degradation, no artificial aging process was performed. For this reason, the results of the present study could be different if long-term water storage, thermocycling, or fatigue methods were employed. Thus, further studies testing long-term durability of these combinations of adhesives and dual-activated cements with nonlight-activated protocol are still needed.

\section{CONCLUSION}

According to the results of this study, the non-lightactivation protocol of simplified adhesives did not influence the shear bond strength of resin cements to a leucite-reinforced glass-ceramic. The universal adhesive presented better performance on bond strength values when compared to the etch-and-rinse simplified adhesive.

\section{Acknowledgments}

The present study was partially supported by he Brazilian National Council for Scientific and Technological Development (grant CNPq 14034/2016-9).

\section{Financial support and sponsorship \\ Nil.}

\section{Conflicts of interest}

There are no conflicts of interest.

\section{REFERENCES}

1. Kelly JR. Dental ceramics: Current thinking and trends. Dent Clin North Am 2004;48:viii, 513-30.

2. Kelly JR, Benetti P. Ceramic materials in dentistry: Historical evolution and current practice. Aust Dent J 2011;56 Suppl 1:84-96.

3. Olivera AB, Marques MM. Esthetic restorative materials and opposing enamel wear. Oper Dent 2008;33:332-7.

4. Manso AP, Silva NR, Bonfante EA, Pegoraro TA, Dias RA, Carvalho RM, et al. Cements and adhesives for all-ceramic restorations. Dent Clin North Am 2011;55:311-32, ix

5. Matinlinna JP, Vallittu PK. Bonding of resin composites to etchable ceramic surfaces - An insight review of the chemical aspects on surface conditioning. J Oral Rehabil 2007;34:622-30.

6. Santos GC Jr., Santos MJ, Rizkalla AS. Adhesive cementation of etchable ceramic esthetic restorations. J Can Dent Assoc 2009;75:379-84.

7. Lührs AK, De Munck J, Geurtsen W, Van Meerbeek B. Composite cements benefit from light-curing. Dent Mater 2014;30:292-301.

8. Vanderlei A, Passos SP, Ö́zcan M, Bottino MA, Valandro LF. Durability of adhesion between feldspathic ceramic and resin cements: Effect of adhesive resin, polymerization mode of resin cement, and aging. J Prosthodont 2013;22:196-202.

9. Chen L, Suh BI. Effect of hydrophilicity on the compatibility between a dual-curing resin cement and one-bottle simplified adhesives. J Adhes Dent 2013;15:325-31.
10. Sanares AM, Itthagarun A, King NM, Tay FR, Pashley DH. Adverse surface interactions between one-bottle light-cured adhesives and chemical-cured composites. Dent Mater 2001;17:542-56.

11. Suh BI, Feng L, Pashley DH, Tay FR. Factors contributing to the incompatibility between simplified-step adhesives and chemically-cured or dual-cured composites. Part III. Effect of acidic resin monomers. J Adhes Dent 2003;5:267-82.

12. Tay FR, Pashley DH, Yiu CK, Sanares AM, Wei SH. Factors contributing to the incompatibility between simplified-step adhesives and chemically-cured or dual-cured composites. Part I. Single-step self-etching adhesive. J Adhes Dent 2003;5:27-40.

13. Tay FR, Suh BI, Pashley DH, Prati C, Chuang SF, Li F, et al. Factors contributing to the incompatibility between simplified-step adhesives and self-cured or dual-cured composites. Part II. Single-bottle, total-etch adhesive. J Adhes Dent 2003;5:91-105.

14. Borges GA, Faria JS, Agarwal P, Spohr AM, Correr-Sobrinho L, Miranzi BA, et al. In vitro marginal fit of three all-ceramic crown systems before and after cementation. Oper Dent 2012;37:641-9.

15. Gaintantzopoulou MD, El-Damanhoury HM. Effect of preparation depth on the marginal and internal adaptation of computer-aided design/computer-assisted manufacture endocrowns. Oper Dent 2016;41:607-16.

16. Ganapathy D, Sathyamoorthy A, Ranganathan H, Murthykumar K. Effect of resin bonded luting agents influencing marginal discrepancy in all ceramic complete veneer crowns. J Clin Diagn Res 2016;10:ZC67-70.

17. Kocaağaoğlu H, Albayrak H, Kilinc HI, Gümüs HÖ. Effect of repeated ceramic firings on the marginal and internal adaptation of metal-ceramic restorations fabricated with different CAD-CAM technologies. J Prosthet Dent 2017;118:672-7.

18. Tay FR, Pashley DH, Suh B, Carvalho R, Miller M. Single-step, self-etch adhesives behave as permeable membranes after polymerization. Part I. Bond strength and morphologic evidence. Am J Dent 2004;17:271-8.

19. Van Meerbeek B, Yoshihara K, Yoshida Y, Mine A, De Munck J, Van Landuyt KL, et al. State of the art of self-etch adhesives. Den Mater 2011;27:17-28.

20. Furuse AY, Santana LO, Rizzante FA, Ishikiriama SK, Bombonatti JF Correr GM, et al. Delayed light activation improves color stability of dual-cured resin cements. J Prosthodont 2016. doi:10.1111/jopr.12509.

21. Calgaro PA, Furuse AY, Correr GM, Ornaghi BP, Gonzaga CC. Influence of the interposition of ceramic spacers on the degree of conversion and the hardness of resin cements. Braz Oral Res 2013;27:403-9.

22. Furuse AY, Glir DH, Rizzante FA, Prochnow R, Borges AF Gonzaga CC. Degree of conversion of a flowable composite light-activated through ceramics of different shades and thicknesses. Braz J Oral Sci 2015;14:230-3.

23. Runnacles P, Correr GM, Baratto Filho F, Gonzaga CC, Furuse AY Degree of conversion of a resin cement light-cured through ceramic veneers of different thicknesses and types. Braz Dent J 2014;25:38-42.

24. Watanabe H, Kazama R, Asai T, Kanaya F, Ishizaki H, Fukushima M, et al. Efficiency of dual-cured resin cement polymerization induced by high-intensity LED curing units through ceramic material. Oper Dent 2015;40:153-62.

25. Hanabusa M, Mine A, Kuboki T, Momoi Y, Van Ende A, Van Meerbeek B, et al. Bonding effectiveness of a new 'multi-mode' adhesive to enamel and dentine. J Dent 2012;40:475-84.

26. Muñoz MA, Luque I, Hass V, Reis A, Loguercio AD, Bombarda NH, et al. Immediate bonding properties of universal adhesives to dentine. J Dent 2013;41:404-11.

27. Sarr M, Kane AW, Vreven J, Mine A, Van Landuyt KL, Peumans M, et al. Microtensile bond strength and interfacial characterization of 11 contemporary adhesives bonded to bur-cut dentin. Oper Dent 2010;35:94-104

28. Peumans M, Kanumilli P, De Munck J, Van Landuyt K, Lambrechts P, Van Meerbeek B, et al. Clinical effectiveness of contemporary adhesives: A systematic review of current clinical trials. Dent Mater 2005;21:864-81

29. Vogl V, Hiller KA, Buchalla W, Federlin M, Schmalz G. Controlled, prospective, randomized, clinical split-mouth evaluation of partial ceramic crowns luted with a new, universal adhesive system/resin cement: Results after 18 months. Clin Oral Investig 2016;20:2481-92.

30. Braga RR, Meira JB, Boaro LC, Xavier TA. Adhesion to tooth structure: A critical review of "macro" test methods. Dent Mater 2010;26:e38-49. 